\title{
Chinese online consumers' responses to web-based data collection efforts: A comparison with American online consumers
}

Received: 8th May, 2001

\section{Yue 'Jeff' Zhang, PhD}

is Assistant Professor of Management Information Systems at the California State University, Northridge. Dr Zhang's recent research interest is in consumer online privacy. He has published in IIE Transactions, Journal of Forecasting, Journal of International Marketing and Marketing Research. Marketing Management Journal, and International Journal of Healthcare Technology and Management.

\section{Charlie C. L. Wang, PhD}

is Associate Processor of Marketing at the University of New Haven. Dr Wang's major research interest is in cross-cultural consumer issues and he has over 15 scholarly publications in referred journals, including Journal of Consumer Psychology, Psychology and Marketing, Journal of Consumer Affairs, Journal of Consumer Marketing, Journal of Global Marketing,Journal of International Consumer Marketing, Journal of Segmentation in Marketing, International Marketing Review, and Journal of Marketing Communications, among others.

\section{Jim Q. Chen}

is Associate Professor of Business Computer Information Systems at St Cloud State University. His current research interests include Web application development methodologies, E-commerce, and executive decision support systems. He has published in Information Systems Management, Systems Development Management, Journal of Computer Information Systems, Logistics Information Management, Total Quality Management, Review of Accounting Information Systems, among other journals.

Yue 'Jeff' Zhang Department of Accounting and MIS, California State University, Northridge, 18111 Nordhoff Street, Northridge, CA 91330, USA. e-mail: jeffyzhang@aol.com

Abstract More and more businesses are trying to build customer database for relationship marketing by collecting data from customers surfing the World Wide Web. Given the substantial resource investment and the global nature of World Wide Web, there is a need for empirical studies on the effectiveness and cross-cultural impact of the online data collection effort. This study attempts to find out the responses to Web-based data collection by Chinese Internet users and the possible factors influencing consumer willingness to participate Web-based surveys. The reasons for answering or not answering the Web survey questions were investigated and compared between groups of gender and occupation. The results are also compared with those found from an American sample.

\section{INTRODUCTION}

As electronic commerce (e-commerce) grows with more intensive competition, e-business enterprises are fighting for more loyal customers. One key to winning over and keeping customers is to personalise the communications and interactions with the customers, which demands a good understanding of the targeted customers. Such a practice demands a good understanding of the targeted customers. As such, in addition 
to building their respective 'Internet Presence Sites' (IPS), more and more businesses attempt to establish and expand databases of customer profiles through the collection of the data about current or prospective customers on the company's website. ${ }^{1}$ In their studies on corporate websites' presence in traditional print advertisements, Pardun and Lamb ${ }^{2}$ found that 68 per cent of the websites attempted to collect data from surfers to develop a database for potential customers. According to a Federal Trade Commission (FTC) study, about 92 per cent of commercial websites collect personal information from users visiting the sites. ${ }^{3}$ By collecting information such as gender, age, marital status, educational level, ethnicity, occupation, household income, Internet usage profile and buying patterns, businesses are able to build useful database for consumer research and relationship marketing. ${ }^{4}$

Attempts at such data collection have, however, often been rejected by some consumers because many Internet users are wary about providing personal information or registering with a site sponsor. $^{5-7}$ Moreover, customers sometimes may just choose to leave the website before going further to register because they do not have the patience to answer the questions if they find such tasks to be time consuming or irrelevant to their surfing objectives. Therefore, while the information gained from this process can be valuable to an advertiser, forcing people to register or to give personal information to gain access to a website may discourage potential visitors.

Customers - current and prospective — may react to data collection efforts differently for different reasons. Customers may be concerned about their privacy; ${ }^{8,9}$ they may lack time to respond $;{ }^{10}$ they may be confused by messages that lack simplicity or comprehensibility. ${ }^{10,11}$ Besides, individual difference variables such as gender, age, occupation, and cultural background may also have an impact on customers' response behaviours $^{12}$ It is, therefore, beneficial, for businesses to understand customer attitudes and response behaviours to web surveys as well as the situations when such data collection efforts will (or will not) work well. A good understanding of what to expect from customers in response to data collection efforts will greatly help businesses to identify potential customers, to serve different groups of customers better and to improve data collection results.

Given the global nature of the Internet, the penetration of a company's website and data collection on the website are reaching an audience of different nations. Due to differences in economic development levels, Internet technology and e-commerce adoption stages, and cultural values and lifestyles, it is expected that different response patterns exist across countries. Studies on the effects of cultural differences on online consumers' responses to Web-based data collection are yet to be conducted; studies on the specific responses of online consumers to data collection efforts in emerging markets are especially warranted. For instance, as one of the most important emerging markets, China has received significant attention from multinational marketers.

Understanding Chinese Internet users' behaviours is important in order to reach them and get their response through the Internet.

China has been undergoing dramatically fast growth in the use of the Internet. The number of Internet users has been going through an explosive development: while in 1996 there were only one million Internet users, the number of Net users quadrupled in less than three years, reaching over four million in mid-1999. By December 2000, the number reached 22.5 
million. ${ }^{13,14}$ Not only are there more and more Chinese online, the Chinese have also become more and more actively involved in e-Commerce activities. According to the CNNIC survey of December 2000, 12.5 per cent of the Chinese respondents reported that their most frequently used Internet application was e-shopping (versus 95.07 per cent for e-mail, 44.65 per cent for information search, and 6.58 per cent for Internet phone, among other uses).

Although Chinese Internet user have been found to be generally willing to participate in web surveys because of the novelty, lack of convenient access, few ISPs and slow transmission speeds, however, impose technical difficulties for them to respond to online data collection requests. ${ }^{15}$

It is imperative to understand Chinese online consumers' attitudinal and behavioural responses to Web-based data collection and factors influencing their willingness to provide the information solicited. The present research is an extension of Zhang, Wang and Chen's 2000 study, which examined the factors that were the most likely to be influencing American consumers' willingness to register on a corporate website by participating in Web surveys. The objective of the current study is to investigate Chinese online users' attitudes toward answering personal questions and to make comparisons with their counterparts in the USA.

\section{DATA COLLECTION}

This study used audiences attending two e-commerce seminars in two major Chinese universities in the summer of 2000 as subjects. The subjects included students (undergraduate and graduate) and working professionals (university faculty and managers from several companies attending short training courses in the
Table 1. Demographic information of Chinese respondents

\begin{tabular}{lll}
\hline & Number & $\%$ \\
\hline Sex & & \\
Female & 22 & 21.57 \\
Male & 68 & 66.67 \\
Unreported & 12 & 11.76 \\
Occupation & & \\
Students & 60 & 58.81 \\
Working professional & 36 & 35.29 \\
Unreported & 6 & 5.88 \\
\hline
\end{tabular}

universities). Surveys were administered to 116 subjects at the beginning of the seminars (to prevent the seminars from biasing or altering the opinions of the subjects). Out of the 116 survey forms returned, 102 were usable and were processed. As indicated in Table 1, the male and female ratio in the sample is about 3 to 1 , which is favourably comparable to the results of the gender composition ratio in the 2001. 'Report on the status of Internet development and usage in China' published by the China National Network Information Center (CNNIC). The authors' use of college-educated Internet users as subjects also largely tallies with the current Internet population in China. According to the aforementioned survey CNNIC, 70.11 per cent of Chinese Internet users are college educated, about 20 times the population proportion of this group (3.6 per cent in the country's population). Therefore, college-educated Chinese Internet users as subjects the for Web-based data collection study should be a fair reflection of the attitudes and behaviours of the Chinese Internet users generally.

The survey asks subjects about their willingness to provide personal information as indicated by their frequency of answering the data collection questions on business websites in a 5-point scale, from 1 ('Never') to 5 ('Always'). The survey then asks the 
Table 2: Reasons to/not to answer questions

\begin{tabular}{lll}
\hline & Percentage & Ranking \\
\hline Reasons to answer & & \\
Product free-trial & 42.2 & 2 \\
Help the company to help customers & 24.5 & 3 \\
Receiving incentive (eg discount/coupon) & 23.5 & 4 \\
Like the company & 20.6 & 5 \\
Being a customer & 19.6 & 5 \\
Prize drawings & 19.6 & \\
& & 1 \\
Reasons not to answer & & 2 \\
Privacy concern & 50 & 3 \\
Not being a customer & 31.4 & 4 \\
Have no time & 15.7 & 5 \\
Inconvenient web-design & 12.8 & \\
Questions asked inappropriately & 12.7 & 1 \\
Information uncomfortable to give & & 2 \\
Income & 59.8 & 3 \\
Consumption pattern & 25.6 & 4 \\
Age & 23.5 & 5 \\
Hobbies & 15.7 & 6 \\
Occupation & 4.9 & 7 \\
Brands used/liked & 2.0 & \\
Education & 1.9 & \\
\hline
\end{tabular}

subjects to choose, based on their experience, the reasons for their answering/not answering the questions. In addition, respondents were asked, in a given list, to indicate the type of personal information that they were most uncomfortable to give.

This information provides a general scenario of an average customer's responses to Web-based data collection efforts. Other personal information, such as occupation and gender of respondents were also collected in order to identify patterns of different customer groups in responding to website marketing efforts.

\section{RESULTS}

\section{A general response pattern to answer Web-based surveys}

The results show that about 67.8 per cent of respondents are willing to provide personal information (from 'sometimes' to 'always') and only 32.2 per cent respondents indicated that they 'seldom' (27.8 per cent) or 'never' (4.4 per cent) answer such questions. These results suggest that the majority of Chinese online consumers are usually willing to provide certain personal information and personal opinions when asked by a company's website. This result is similar to the result from a previous study with an American sample ${ }^{16}$ and it shows a fairly good general response rate to Web-based collection data activities.

\section{Major factors influencing willingness to answer}

Table 2 provides the descriptive percentage and rankings of the reasons that a subject answers/does not answer the Web-based data collection questions. The results suggest that a 'product free trial' is the top reason for customers answering data collection questions. All other factors follow at a distance, with 'help the company to help customers', 'receiving discounts/coupons', and 'like the company and want to help' being the second, third and fourth ranked reasons, respectively. The least likely 
reasons are 'being a customer' and 'prize drawings'. The reason 'free trial' was ranked the most important motivation may be explained by business practices in China. Until now, most Chinese businesses have not made product return/refund and warranty a routine business practice. Therefore, a free trial offers a good way for consumers to try out the functionalities of a product or service with no or low risk. Compared with a free trial, discount or coupon still require that the consumer pays a certain amount, while getting a prize from a draw would sound too unlikely to a rational consumer. On the other hand, respondents indicate 'privacy concern' as the most likely reason (50 per cent) for not wanting to answer the questions. 'Not a customer of the company' is listed as the next most important reason (31.4 per cent) for respondents not answering the questions. The other three reasons: 'have no time', 'inconvenient Web design,' and 'inappropriate way of asking questions' get similar responses (15.7 per cent, 12.8 per cent, and 12.7 per cent, respectively). These results are consistent with previous findings based on American samples that web surfers often refused to provide personal information because of concerns about privacy. ${ }^{17,18}$ Respondents also tend not to answer questions if they are 'not a customer and not considering becoming one' and 'have no time.' This suggests that lack of motivation/incentive (not being a customer) or the presence of negative incentive (waste of time) are factors keeping the customers from answering the questions. The 'facilitating' factors (eg design of the Web page or phrasing of questions) have a relatively minor influence.

While the above results revealed a general pattern of respondents' willingness to provide information to website data collection it should be noted that not all personal data are equally sensitive to respondents Among different cultures, the degree of sensitivity of personal information may be very different. An interesting question for website data collectors is, then, what types of information are more sensitive to respondents (in this case, Chinese) and that are less likely to generate replies, and what types of questions lead to a higher response rate. As shown in Table 2 , respondents generally felt most 'uncomfortable' or 'unwilling' giving that information regarding 'personal income' (59.8 per cent). Therefore, if a company intends to generate high customer involvement and response to its website, it might be better not to include personal income questions unless they are absolutely necessary to the company's objectives. Otherwise, potential customers may simply leave the website without answering any questions.

It is noteworthy that Chinese Internet users find it uncomfortable to provide online such personal information as 'consumption pattern of products/services' and 'age' (25.6 per cent and 23.5 per cent respectively). While 'hobbies' accounts for a non-trivial weight as sensitive information, 'occupation,' 'favourite brands,' and 'education' are almost negligible in terms of concerns about information sensitivity. There are differences between Chinese and American Internet users on the relative sensitivity of the personal information on the above items. Such differences will be discussed later.

\section{Demographic differences}

One of the major advantages of e-commerce is to allow businesses to conduct interactive marketing targeting to well-defined niche markets. ${ }^{19,20}$ Knowing the characteristics of subgroups of users or niche markets presents 
Table 3: Comparisons of Chinese female and male respondents (in percentage)

\begin{tabular}{llll}
\hline & Females & Males & Chi-Square \\
\hline Reasons to answer & & & \\
Being a customer & 31.8 & 16.2 & 2.54 \\
Receiving discounts/coupons & 31.8 & 25 & 3.95 \\
Prize drawings & 18.2 & 23.5 & 0.28 \\
Product free-trial & 36.4 & 41 & 0.6 \\
Help the company & 13.6 & 29.4 & 2.17 \\
Like the company & 31.8 & 20.6 & \\
& & & \\
Reasons not to answer & & 20.6 & $9.33^{\star \star \star}$ \\
Not being a customer & 54.5 & 54.4 & 0 \\
Privacy concern & 54.5 & 10.3 & $0.36^{\star \star}$ \\
Have no time & 31.8 & 13.2 & 0.33 \\
Inconvenient Web-design & 18.2 & 13.2 & \\
Questions asked inappropriately & 18.2 & & 1.84 \\
Information uncomfortable to give & & 27.9 & 1 \\
Age & 13.6 & 4.4 & 1 \\
Occupation & 0 & 4.4 & 1.51 \\
Education & 0 & 64.7 & $3.11^{\star}$ \\
Income & 50 & 5.9 & 0 \\
Hobbies & 18 & 0 & $11.57^{\star \star *}$ \\
Brands used/liked & 0 & 17.6 & \\
Product consumption pattern & 54.5 & & \\
\hline
\end{tabular}

Note: ${ }^{\star} p<.1 ;{ }^{\star \star} p<.05 ;{ }^{\star \star \star} p<.01$

important opportunities for the right marketers. ${ }^{21,22}$ There is further interest, then, in identifying the demographic differences (eg gender and occupation) in willingness to answer data questions. While an overall pattern indicated that female respondents tend to be less willing than male respondents to answer Web-based survey questions $(t=4.69$, $\mathrm{p}<.01)$, results in Table 3 show that, in particular, female respondents were less likely than their male counterparts to answer survey questions if they were not considering being customers $\left(\chi^{2}=9.33\right.$, $\mathrm{p}<.01)$ and when they felt they had no time $\left(\chi^{2}=5.86, \mathrm{p}<.05\right)$. Females also felt more uncomfortable than males giving personal information about hobbies $\left(\chi^{2}=3.11, \mathrm{p}<.1\right)$ and their consumption patterns $\left(\chi^{2}=11.57\right.$, $\mathrm{p}<.01)$.

As regards occupation, working professionals, in general, were found to be more willing to answer questions than students $(t=3.67, \mathrm{p}<.01)$. When broken down into categories, as reported in Table 4, however, quite different response patterns were observed between the two groups. Students considered 'prize drawings' $\left(\chi^{2}=5.45, \mathrm{p}<.05\right)$ and 'product free-trial' $\left(\chi^{2}=7.38, \mathrm{p}<.01\right)$ as more important reasons for responding to Web surveys. In contrast, working professionals rated 'help the company' $\left(\chi^{2}=2.78, \mathrm{p}<.1\right)$ and 'like the company' $\left(\chi^{2}=4.43, \mathrm{p}<.05\right)$ significantly higher than students did as reasons for answering the survey questions. These results suggest that while students put more emphasis on incentives for participating in surveys, professionals respond more on the basis of goodwill to companies. Besides, in terms of 'reasons not to answer' survey questions, students were rated higher than professionals on 'not being a customer' $\left(\chi^{2}=12.1, \mathrm{p}<.01\right)$, 'privacy concern' $\left(\chi^{2}=15.63, \mathrm{p}<.01\right)$ and 'inconvenient web-design' $\left(\chi^{2}=9.22\right.$, $\mathrm{p}<.01)$. On the other hand, professionals rated higher than students on 'have no time' $\left(\chi^{2}=2.88, p<.1\right)$ and 'questions 
Table 4: Comparisons of Chinese students and professionals (in percentage)

\begin{tabular}{llll}
\hline & Students & Professionals & Chi-Square \\
\hline Reasons to answer & & & \\
Being a customer & 15 & 25 & 1.47 \\
Receiving incentive (eg coupon) & 20 & 33.3 & 2.13 \\
Prize drawings & 28.3 & 8.3 & $5.45^{\star \star}$ \\
Product free-trial & 53.3 & 25 & $7.38^{\star \star \star}$ \\
Help the company & 18.3 & 33.3 & $2.78^{\star}$ \\
Like the company & 15 & 33.3 & $4.43^{\star \star}$ \\
Reasons Not to Answer & & & \\
Not being a customer & 41.7 & 8.3 & $12.1^{\star \star \star}$ \\
Privacy concern & 66.7 & 25 & $15.63^{\star \star \star}$ \\
Have no time & 11.7 & 25 & $2.88^{*}$ \\
Inconvenient web-design & 21.7 & 0 & $9.02^{\star \star \star}$ \\
Questions asked inappropriately & 8.7 & 25 & $6.45^{\star \star}$ \\
Information uncomfortable to give & & & \\
Age & 21.7 & 25 & 0.14 \\
Occupation & 0 & 8.3 & $5.16^{\star \star}$ \\
Education & 0 & 8.3 & $5.16^{\star \star}$ \\
Income & 63.3 & 58.3 & 0.24 \\
Hobbies & 20 & 0 & $8.23^{\star \star \star}$ \\
Brands used/liked & 3.3 & 0 & 1.23 \\
Product consumption pattern & 43.3 & 0 & $21.39^{\star \star \star}$ \\
\hline
\end{tabular}

Note: ${ }^{*} p<.1:{ }^{\star \star} p<.05 ;{ }^{\star \star \star} p<.01$

asked inappropriately' $\left(\chi^{2}=6.45\right.$, $\mathrm{p}<.05)$. This may reflect the fact that working professionals are more time-conscious than students. Moreover, students felt more uncomfortable than professionals about giving information about their hobbies $\left(\chi^{2}=8.23, \mathrm{p}<.01\right)$ and product consumption patterns $\left(\chi^{2}=21.39, \mathrm{p}<.01\right)$, whereas professionals felt more uncomfortable than students about giving information about occupation $\left(\chi^{2}=5.16, \mathrm{p}<.05\right)$ and education level $\left(\chi^{2}=5.16, p<.05\right)$.

\section{Comparisons between Chinese and American Internet Consumers}

As more US-based international businesses expand their operations in China, it is useful for these companies to understand the cultural differences which would be reflected in consumer attitudinal and behavioural responses towards Web-based data collection. The current study, as a cross-national extension of a similar study using an American sample $\mathrm{e}^{23}$ based on the same survey instrument, also compared results from the two countries. While there was no overall difference $(t=.36$, $p>.1)$ between the two countries in terms of willingness to answer data collection questions, there were differences in particular response patterns, as shown in Table 5 .

The results showed that American respondents were more likely than their Chinese counterparts to answer Web questions if they were interested in being a customer $\left(\chi^{2}=28.85, \mathrm{p}<.01\right)$ and if there were incentives such as coupons $\left(\chi^{2}=16.2, \mathrm{p}<.01\right)$ and prize draws $\left(\chi^{2}=13.06 \mathrm{p}<.01\right)$. On the other hand, Americans were more likely than Chinese 'not to answer' when they felt they were spending too much time in answering the questions $\left(\chi^{2}=59.37\right.$, $\mathrm{p}<.01)$, or the questions were not appropriately asked $\left(\chi^{2}=6.51, \mathrm{p}<.05\right)$, or if they have no interest in being a customer $\left(\chi^{2}=6.93, p<.05\right)$. In 
Table 5: Comparisons of American and Chinese respondents (in percentage)

\begin{tabular}{llcc} 
& Americans & Chinese & Chi-Square \\
\hline Reasons to answer & & & \\
Being a customer & 53.3 & 19.6 & $28.85^{\star *}$ \\
Receiving discounts/coupons & 48.7 & 23.5 & $16.20^{\star *}$ \\
Prize drawings & 41.3 & 19.6 & $13.06^{\star *}$ \\
Product free-trial & 42 & 42.2 & 0.01 \\
Help the company & 28 & 24.5 & 0.38 \\
Like the company & 20 & 20.6 & 0.01 \\
& & & \\
Reasons not to answer & 48 & 31.4 & $6.93^{\star *}$ \\
Not being a customer & 56 & 50 & 0.88 \\
Privacy concern & 64 & 15.7 & $57.37^{\star *}$ \\
Have no time & 11.3 & 12.8 & 0.12 \\
Inconvenient web-design & 26 & 12.7 & $6.51^{*}$ \\
Questions asked inappropriately & & & 3.76 \\
Information uncomfortable to give & 14 & 23.5 & $14.64^{\star *}$ \\
Age & 22.7 & 4.9 & $5.19^{*}$ \\
Occupation & 10.7 & 1.9 & $9.69^{\star *}$ \\
Education & 78 & 59.8 & 2.39 \\
Income & 9.3 & 15.7 & $4.22^{\star}$ \\
Hobbies & 8.0 & 2.0 & 0.07 \\
Brands used/liked & 24 & 25.6 &
\end{tabular}

Note: ${ }^{*} p<.05 ;{ }^{*} p<.01$

addition, Americans felt more uncomfortable than their Chinese counterparts about giving personal information such as occupation $\left(\chi^{2}=14.64, \mathrm{p}<.01\right)$, education level $\left(\chi^{2}=5.19, \mathrm{p}<.05\right)$, personal income $\left(\chi^{2}=9.69, \mathrm{p}<.01\right)$ and brand preference $\left(\chi^{2}=4.22, \mathrm{p}<.05\right)$.

The reasons for the above differences can be explained by differences in cultural values, lifestyles and common business practices. Since the USA is a more commercial society with a faster pace in daily life, ${ }^{24}$ it is expected that American Internet users would be less patient than Chinese in spending time answering the Web-based data collection questions. As indicated earlier, a comparable result was observed within the Chinese sample in that professionals were less likely than students to answer questions when time is a concern.

Differences in business practices in the USA and China also contribute to the differences in attitudes and behaviours of
Internet users of the two countries. E-commerce is still less developed in China, where significantly fewer numbers of customers are involved in online shopping due to various barriers such as less common use of credit cards for payment. As such, Chinese Internet users' willingness to answer Web-survey questions was less contingent upon 'being customers' status than their US counterparts. Coupons as an incentive in the Chinese market has not yet become prevalent. While prizes have been widely used by companies, this selling tactic has a bad reputation because of deceptive practices of some companies and they generally generate suspicion especially among more educated consumers, as found with the subjects in the current study. That is why coupons and prize drawings did not motivate Chinese Internet users as much as they did American Internet users. This result is also comparable with a survey conducted by Cheskin Research Inc., which 
concluded that mainland Chinese required little incentive to respond to an Internet survey due to its relative novelty. ${ }^{25}$

Lastly, as an individualistic society, American culture emphasises individual privacy more than Chinese society does. ${ }^{26}$ Therefore, it would not be surprising to observe that American respondents are more sensitive than Chinese respondents to giving personal information about occupation, education, income level and even brand preferences.

\section{CONCLUSIONS}

This study has found that Chinese Internet users are generally willing to provide personal information online for various benefits. The top motivation for them is 'free trial'. Chinese Internet users are mostly reluctant to give personal information because of privacy concerns. While the status of being a customer is not a strong motivation for someone to give data, not being a customer is more likely to be a hindrance. Therefore, the data collection efforts of businesses should still be largely focused on their existing customers. Chinese Internet users care very much about data income, as well as about consumption pattern and age. Businesses trying to collect data on their websites should consider the above findings in the design of their Web-based questionnaire/registration.

In addition to the overall response patterns, differences were found between gender and occupation groups. Female Chinese Internet users are less willing than their male counterparts to give out their personal information, and they tend to refuse to answer data collection questions if they are not customers of the company or they do not have time to answer the questions. Chinese women are found to see hobbies and consumption patterns as more sensitive information than men do.
Between different occupations, working professionals are more willing to answer data collection questions, and are more likely to do so out of goodwill, while students are more likely to be lured by incentives. Chinese students are more likely to be held back from providing personal data for reasons such as 'not being a customer' and 'privacy concern'. In contrast, working professionals are more likely to be held back by lack of time and by questions being asked in an inappropriate way. Chinese students tend to see lifestyle information as more sensitive, while working professionals are concerned more about their own demographic data. Web-based questionnaire/registration designs should take these differences into account, according to a company's targeting objectives.

Cultural and lifestyles differences between American and Chinese societies do play a part in consumers' responses to Web-based data collection. American respondents were more likely than their Chinese counterparts to answer surveys if they were a customer or interested in being a customer, and if there were incentives such as coupon or prize draws. Americans were more likely than Chinese to refuse to answer questions for such pragmatic reasons as not being a customer or time consumption, and for more operational or perceptual reasons as the way the questions were asked.

Americans have more categories of personal information they are uncomfortable about giving, reflecting a higher level of privacy awareness and privacy concerns. The understanding of these differences between the two cultures and societies would be valuable to US-based multinational companies seeking to enter and expand into the Chinese e-market.

Corporate home pages allow consumers to request brochures, 
communicate comments and questions to the corporation and find other related information. A challenge facing companies marketing on the Web is to understand Internet users in terms of different demographic backgrounds. Gathering demographic information from people visiting a company website is one way to identify the target audience. What seems applicable to both American and Chinese users is that it would be more cost efficient to increase survey responses by focusing on existing customers while providing incentives to encourage Web surfers to become customers. Website designers and researchers face a challenge in developing website data collection methods that respondents will feel are less time-consuming, less intrusive, and more convenient to answer. Besides improving the content of survey questions, some technical issues should also be considered. As Shimamoto suggested, Web-based surveys should be streamlined to allow faster download and response times. Stripping out unnecessary graphics, backgrounds and fancy fonts will also help improve response rates.

\section{References}

1 Masci, D. (1999) 'Internet privacy', In Sandra, L. S. (ed.) 'Issues for debate in American public policy', CQ Press Washington DC. pp.175-91.

2 Pardun, C. F. and Lamb, L. (1994) 'Corporate websites in traditional print advertisements', Internet Research Vol. 9, no. 2, pp. 93-99.

3 Federal Trade Commission (1998). 'Privacy online: A report to the Congress'.

4 Turban, E. Lee, J. King, D. and Chung, H. M. (2000) 'Electronic commerce: A managerial perspective', Prentice Hall, New Jersey.

5 Camp, L. J. (1999) 'Web security and privacy: an
American perspective', The Information Society, Vol. 15, pp. 249-256.

6 Caudill, E. M, Murphy, P. E. (2000) 'Consumer online privacy: legal and ethical issues', Journal of Public Policy and Marketing, Vol, 19, No. 1 pp. 7-19.

7 O’Guinn, T. C. Allen, C. T. Semenik, R. J. (2000) 'Advertising', Southwest College Publishing.

8 Turban et al. (2000) op. cit.

9 Schneider, G. P. and Perry, J. T. (2000) 'Electronic commerce', Course Technology-ITP, Massachusetts.

10 Kalakota, R. and Whintson, A. B. (1996) 'Frontiers in electronic commerce', Addison-Wesley, Massachusetts.

11 Kalakota, R. and Whintson, A. B. (1997) 'Readings in electronic commerce', Addison-Wesley, Massachusetts.

12 Zhang, Y., Wang, C. and Chen, J. (2000) 'Consumers' responses to Web-based data collection efforts and factors influencing the responses', Journal of International Marketing and Marketing Research, Vol, 25, No. 3, pp. 115-23.

13 China National Network Information Center (CNNIC) (1999) 'The status of Internet development in China', in Chinese, available at: http://www.cnnic.net.cn/develst/cnnic199907.shtml, accessed 15th February 2001.

14 China National Network Information Center (CNNIC), (2001) 'The status of Internet development in China', in Chinese, available at: http://www.cnnic.net.cn/develst/cnnic200101.shtml, accessed 15th February 2001.

15 Shimamoto, N. (2000) 'Chinese checkers: Internet crucial link to research in China', Marketing News, 23rd April, pp. 39, 42.

16 Zhang et al. (2000) op. cit.

17 O'Guinn et al. (2000) op. cit.

18 Zhang et al. (2000) op. cit.

19 Turban et al. (2000) op. cit.

20 Hanson, W. (2000) 'Principles of Internet marketing', Southwest College Publishing.

21 O'Guinn et al. (2000) op. cit.

22 Moon, M. (1998) 'Hitting your target: Seven strategies for Web-integrated marketing', New Media, 5th May pp. 40-50.

23 Zhang et al. (2000) op. cit.

24 Kenna, P. and Lacy, S. (1994) 'Business China', Passport Books, Illinois.

25 Shimamoto et al. (2000) op. cit.

26 Kenna and Lacey et al. (2000) op. cit. 